\title{
Global epidemiology of Zika and Chikungunya virus human infections
}

\author{
Silvia Zannoli, ${ }_{1}^{1}$ Manuela Morotti, ${ }_{1}^{1}$ Agnese Denicolò, ${ }^{1}$ Martina Tassinari, ${ }^{1}$ Claudia Chiesa, ${ }^{1}$ Anna Pierro, ${ }^{1}$ \\ Vittorio Sambri ${ }^{1,2}$
}

${ }^{1}$ Unit of Microbiology, The Great Romagna Hub Laboratory, Pievesestina; ${ }^{2}$ DIMES, University of Bologna, Italy

\section{Summary}

Zika virus was discovered in 1947 . The first reported case of Zika fever was in a sentinel rhesus monkey in Uganda in 1947, while the first human cases were reported in Nigeria in 1954. Since the first evidence of human infection, Zika was active in several countries in Africa and Asia, as sporadic cases and serological evidence of Zika human infections have been demonstrated in several reports. The outbreak of Zika in Yap Island in 2007 is considered the first emergency of this infection. Since then Zika has spread worldwide with a large ongoing epidemic in South and Central America. A huge concern nowadays is about the relationship between Zika infection and microcephaly and about the sexual transmission of the virus. The first identified outbreak of Chikungunya human infection, with an incidence estimated at 23\%, was reported from July 1952 to March 1953 in the Southern Province of the current Tanzania. Since then Chikungunya circulated mainly in continental Africa with limited outbreaks. The virus started to spread east bound involving most of the areas surroundings the Indian Ocean. In 2004/2005 a large outbreak developed in La Reunion a French territory in the Indian Ocean: from this point Chikungunya spread to India and from there, due a viraemic traveller returning from Kerala, to Italy where in the

Correspondence: Silva Zannoli, Unit of Microbiology, The Great Romagna Hub Laboratory, Piazza della Liberazione 60 - 47522 Pievesestina (FC), Italy.

Tel.: +39.0547.394805 - Fax: +39.0547.394865.

E-mail: silvia.zannoli@gmail.com

Key words: Zika virus, Chikungunya virus, Epidemiology.

Contributions: SZ, MM, MT, CC and AdN wrote the manuscript, AP reviewed the manuscript, VS devised the project and reviewed the manuscript.

Conflict of interest: the authors declare no potential conflict of interest.

Received for publication: 7 September 2017.

Accepted for publication: 8 September 2017.

(C) Copyright S. Zannoli et al., 2017

Licensee PAGEPress, Italy

Microbiologia Medica 2017; 32:7054

doi:10.4081/mm.2017.7054

This article is distributed under the terms of the Creative Commons Attribution Noncommercial License (by-nc 4.0) which permits any noncommercial use, distribution, and reproduction in any medium, provided the original author(s) and source are credited. summer of 2007 the first outbreak with local viral transmission in a temperate climate zone occurred. In the following years Chikungunya moved to the Caribbean and South America. Recently also the USA experienced the spread of this virus and a limited outbreak based again on local spreading occurred in the French Department of Var, in August 2017.

\section{Zika epidemiology}

\section{Reported cases}

Zika virus (ZIKV) was discovered in 1947. The first reported case of Zika fever was in a sentinel rhesus monkey in Uganda in 1947, while the first human cases were reported in Nigeria in 1954 (32). In 1954 a serological surveillance study in French Equatorial Africa showed only $0.5 \%$ were positive for Zika antibodies. Since the first evidence of human infection, Zika was active in several countries in Africa and Asia, as sporadic cases and serological evidence of Zika reported in surveys and case reports demonstrated (104). In Nigeria (1971-1975), 38\% of the individuals had neutralizing antibodies to Zika in sera and Zika Virus was confirmed by serologic test in $3.1 \%$ of febrile patients in an hospital in Java, Indonesia (1977-1978) (97).

From 1983 until 2006, there were no publications about Zika Virus, until the Yap Island outbreak in 2007, the first major outbreak ever reported, with 185 confirmed cases. It was detected for the first time in Oceania (91). The attack rate in Yap State, located at the Federated States of Micronesia in the Western Pacific was 14.6 per 1000 inhabitants and the mean age was 36 years (24). It was estimated a Zika infection rate (positive immunoglobulin M) of $73 \%$ (95\% confidence interval, CI: $68 \%, 77 \%)$, and clinical manifestations in approximately 1 in every 5 infected people (44). Yap State, located at the Federated States of Micronesia in the Western Pacific, estimated that over $72 \%$ of their residents over 3 years of age were infected with ZIKV (89). A total of 108 cases were confirmed by PCR or serology, 72 cases remained suspected, and no deaths were reported. The most common symptoms were rash, fever, arthralgia and conjunctivitis. The most probably vector of transmission was the mosquito Aedes hensilli, the predominant species identified during the Yap Island outbreak. A hypothesis regarding the way of introduction of Zika Virus had been raised: a viremic person travelling from the Philippines could have introduced it (9). Yap Island outbreak was also the first time Zika fever had been reported outside Africa and Asia (46).

From 2008 to 2013, 4 studies were published on Zika: 3 case reports and 1 surveillance study. Three cases of Zika occurred in Senegal and Colorado. It seems that two scientists acquired ZIKV in Senegal and then they returned home to Colorado, where one of them transmitted the virus to his wife via semen (38). Two cases 
of Zika virus were reported in Cambodia $(48,49)$, while the surveillance study was conducted in Cameroon (36).

There were no other publications about Zika Virus in the Pacific region until 2013, when another large outbreak was reported in French Polynesia. It seems that this one had an independent virus introduction than the Yap Island outbreak (98). It was the largest Zika virus outbreak until that moment. From October to April 2014 it was estimated that $3000-32,000$ people (11.5\% of the entire population) used the health facilities with Zika-like symptoms (29). A total of 383 cases were confirmed by serology and the mean age of those patients was 28 years (75). A serological surveillance study conducted from 2013 to 2014 among blood donors found that $2.8 \%$ were reverse-transcription polymerase chain reaction (RT-PCR) positive for ZIKV. Out of the positive donors, $26.2 \%$ reported Zika fever-like disease from 3 to 10 days after blood donation (90).

During this outbreak there was an increase in the number of neurological and autoimmune complications: 2.3 cases per 1000 showed neurological complications and 1.3 cases per 1000 (42 cases) had Guillain-Barré Syndrome (GBS), suggesting a possible association between ZIKV and GBS (29). Among the GBS cases, $88 \%$ reported a viral syndrome up to 23 days before the beginning of the neurological syndrome. One case was confirmed by RTPCR, while several other cases were found to be immunoglobulin G-positive against Zika after the neurological signs. The mean age of those patients was 46 years, $74 \%$ were men and no deaths cases were reported, even if fifteen cases required intensive care, and 9 needed mechanical ventilation $(29,75)$. French Polynesia authorities identified 17 cases of malformations in fetuses and newborns (28) None of the pregnant women reported clinical signs of Zika, but the serological test performed in 4 women showed that they were immunoglobulin G-positive for flavivirus, suggesting a possible asymptomatic Zika infection (28). Two cases of perinatal ZIKV transmission was reported in French Polynesia from 2013 to 2014 (3).

The French Polynesian outbreak quickly spread to other Pacific islands (89). New Caledonia health authorities declared a ZIKV outbreak in February 2014, and by the end of August, 1400 cases had been reported $(116,149)$. Cook Islands declared a Zika Virus outbreak in March 2014 with 905 cases reported (134). Also Fiji, Samoa, and Solomon Island reported autochthonous cases. Other countries, such as Philippines (1) and Thailand (5) reported several ZIKV cases. Also Japan (66), Australia (110), Italy (154), Germany (130), Norway (140), Canada (37), United States (78) and United Kingdom (50) reported imported cases without autochthonous transmission.

Chile health authorities reported the first autochthonous case of Zika Virus on 28 January 2014. At the end of the outbreak 51 of 89 samples from suspected cases of Zika were confirmed by RT-PCR and female were more likely to have Zika infection than males (8).

In May 2015, the Pan American Health Organization (PAHO) issued an alert regarding the first confirmed Zika virus infections in Brazil (155). Serum samples from 24 exhantematic patients from Camaçari, Bahia, Brazil, were tested by RT-PCR and seven of them presented were confirmed for Zika Virus. In December 2015 Brazil reported autochthonous virus transmission (51).

Statistical research estimated that the number of suspected cases of ZIKV infection ranged from 440,000 to $1,300,000$ by the end of 2015 (118).

In Bahia the attack rate in 2015, detected among reported cases, was approximately 4.4 per 1000 inhabitants and some cities, such as Camaçari, Itabuna, Senhor do Bomfim, and Monte Santo, have an attack rate greater than 25 per 1000 inhabitants (149).

Ten of 224 samples from suspected cases of Zika Virus were confirmed and 7 of those had also a neurological syndrome. Brazilian authorities reported an increase in the number of neurological manifestations and GBS during the outbreak. In Bahia, the proportion of neurological complications temporally associated with Zika was 2.3 per 1000 detected among reported cases (81), while GBS was diagnosed in 1 of every 1000 reported cases. Zika virus is suspected to be the cause of 2400 cases of microcephaly and 29 infant deaths in Brazil in 2015 (28). The mode of introduction of ZIKV in Brazil remains uncertain, but it has been hypothesized that the virus was introduced during the soccer World Cup event held in Brazil in 2014 (87), or during the World Spring Canoe championship held in Rio de Janeiro in 2014, from a viraemic athlete from one of the participating Pacific countries, or during the 2013 Confederations Cup soccer tournament (34). ZIKV introduction went probably initially unnoticed because Zika Virus clinical symptoms can be confused with those caused by two endemic virus in Brazil: dengue and chikungunya. Brazil authorities have notified 120,161 probable cases and 39,993 confirmations until the 16th epidemiological week of 2016 (101). On 1st February 2016, the WHO declared the ZIKV epidemic in Brazil a Public Health Emergency of International Concern (46).

The emergence of Zika virus in South America had a rapid spread throughout South and Central America, reaching Mexico in November 2015 (46). Because of the growing evidence of a link between Zika and microcephaly the CDC issued a travel alert on January 15, 2016 advising pregnant women or women thinking about becoming pregnant to postpone travel to the following countries and territories: Brazil, Colombia, El Salvador, French Guiana, Guatemala, Haiti, Honduras, Martinique, Mexico, Panama, Paraguay, Suriname, Venezuela, and the Commonwealth of Puerto Rico (98).

In an epidemiological update from 2 June 2016 the Pan American Health Organization (PAHO) identified 39 countries and territories in the Region of the Americas have confirmed local, vector-borne transmission of ZIKV since 2015 (41).

In the past 5 years, 163 cases (5.6 per 100,000 live births) of microcephaly were identified each year, according to routine birth reports. In 2015, there were 3530 (121.7 per 100,000 live births) suspected cases of microcephaly reported including 46 deaths, mainly in Pernambuco, where there were concentrated $35 \%$ of the total of suspected cases of microcephaly (100).

ZIKV RNA was found in amniotic fluid samples from 2 pregnant women with foetal microcephaly (80). The two women had Zika-like symptoms at gestation weeks 18 and 19. Currently, autochthonous Zika transmission has occurred in 27 counties in the Americas, such as Colombia (16,419 reported cases; $66.4 \%$ were female; 798 laboratory-confirmed cases); Guatemala (17 suspected cases); Mexico (confirmed local transmission); Panama (3 cases); Paraguay (6 laboratory-confirmed cases); Venezuela (4 laboratoryconfirmed cases, 15 GBS cases); El Salvador (240 cases, 46 GBS cases, $54 \%$ of them male, and 2 deaths); Honduras, and Martinique. Bolivia, Guyana, Ecuador, Guadeloupe, Guatemala, Puerto Rico, Barbados, Saint Martin, and Haiti have reported sporadic transmission following recent introduction (30).

Death attributed to ZIKV are rare, however some deaths caused to ZIKV have been reported (98). Brazilian Health Official reported three cases of people died for ZIKV complication until May 2016, four death were reported in Colombia and three in Venezuela (101).

The importation of ZIKV cases to areas where competent mosquitoes are present poses a risk of mass dissemination of ZIKV globally. This most recent information demonstrates the extraordinary capacity of ZIKV to rapidly spread to non-endemic areas throughout the world where the mosquito vector is present (154). 


\section{Vectors}

Zika is a mosquito-borne RNA virus belonging to the Flaviviridae family that can causes a not specific disease in humans. Zika virus's reservoir is not clearly identified, but it is supposedly maintained in a sylvatic cycle involving non-human primates and several Aedes species as mosquito vectors. Infection in humans is acquired after a bite by a female infective mosquito in endemic countries. The virus is endemic in Africa and south-east Asia: a phylogenetic analysis based on sequencing of non-structural protein gene (NS5) reveals two main distinct lineages. The African lineage has mostly a zoonotic cycle between non-human primates and mosquitos of Aedes species; it can also be transmitted to humans in urban areas. It spreads in Uganda, Central African Republic, Senegal, Nigeria and rural areas of tropical sub-Saharan Africa (35).

The Asian lineage has a zoonotic cycle between non-human primates and arboreal Aedes spp; it can also be transmitted to human. It is responsible of cases from the South Pacific, the Americas, Europe and Asia. (13)

Zika Virus has been isolated from different species of Aedes mosquitos, but other species, such as some anopheles, culex and mansonia have been proposed as possible vectors (13). Aedes species present special difficulty to vector control agencies, because they can reproduce in very small amounts of water and their eggs are extremely hardy, and can survive drying for more than a year.

The first isolation was in 1948 from Aedes africanum in the Uganda forest: since then, it has been isolated in sylvatic mosquitos of Aedes spp (Ae. furcifer, Ae. vittatus, Ae. luteocephalus and Ae. apicoargenteus). Aedes hensilli was implicated in the spread of ZIKV on Yap Island (South Pacific) of 2007, while Aedes polynesiensis was probably the main vector in the French Polynesian outbreak of 2013. These mosquitoes are probably involved in transmission of ZIKV to humans, however Aedes aegypti and Aedes albopictus (Asian tiger mosquito) are the main vectors (151). Both of this two mosquitos have been implicated in large outbreak of Zika virus.

Distribution of Aedes aegypti is limited to hot wet regions and cannot easily spread to other areas: it is currently distributed in Africa, South-Eastern US, the Middle East, South-East Asia, Pacific and Indian Islands and Northern Australia. Reports from
Europe show its presence in Madeira, Netherlands and north-eastern Black Sea coast (Figure 1) (132,156).

Ae albopictus, conversely, has a widespread distribution, even in temperate regions. This mosquitoes adapted themselves to cooler regions: they are active all year long in tropical region, while they hibernate over winter in temperate regions. During the past three decades, with passive transport of eggs in used tyres and lucky bamboo, Ae albopictus has spread from Asia and established in South Pacific, the Middle East, Europe, Africa, the Americas and the Caribbean (Figure 2) $(62,63,85,103,157)$.

The ability of the mosquito to transmit ZIKV depends on the combination of its competence (biological capability to transmit a virus) and capacity (efficiency with which it transmits a disease). Ae aegypti and Ae albopictus have similar characteristics, even if the capacity of Ae albopictus is lower (Table 1).

Recently a large increase in the circulation of ZIKV was observed worldwide, which initially was endemic only in Africa and Asia. It is now spreading in the Americas, above all in Latin America, but cases have been reported even in Europe and Oceania. Autochthonous transmission is established in countries like Brazil, where a large concentration of cases is observed. Travellers from these countries are able to introduce Zika virus into new countries, where Aedes vectors can become infected and maintain the local transmission cycles (Figure 3).

\section{Transmission}

Aedes Aegypti and Aedes albopictus mosquitoes are the most important vectors in the urban transmission cycle of ZIKV (39). These mosquitoes are highly susceptible to ZIKV infection in vitro, with potential for further transmission after an extrinsic incubation period of 5-10 days (145). Ae. aegypti and Ae. albopictus usually lay eggs near still water and bite both indoors and outdoors, mostly during daytime. Mosquitoes become infected when they feed on a person already infected, then they can then spread the virus to other people through bites (145).

Even if mosquito bites are the main mode of transmission, some cases of non-vector-borne infection have been reported. A pregnant woman already infected with ZIKV could transmit the virus to the foetus during pregnancy or around the time of birth. The perinatal transmission is probably caused by viral crossing of the placenta or by viraemic mothers delivery, and mother and baby
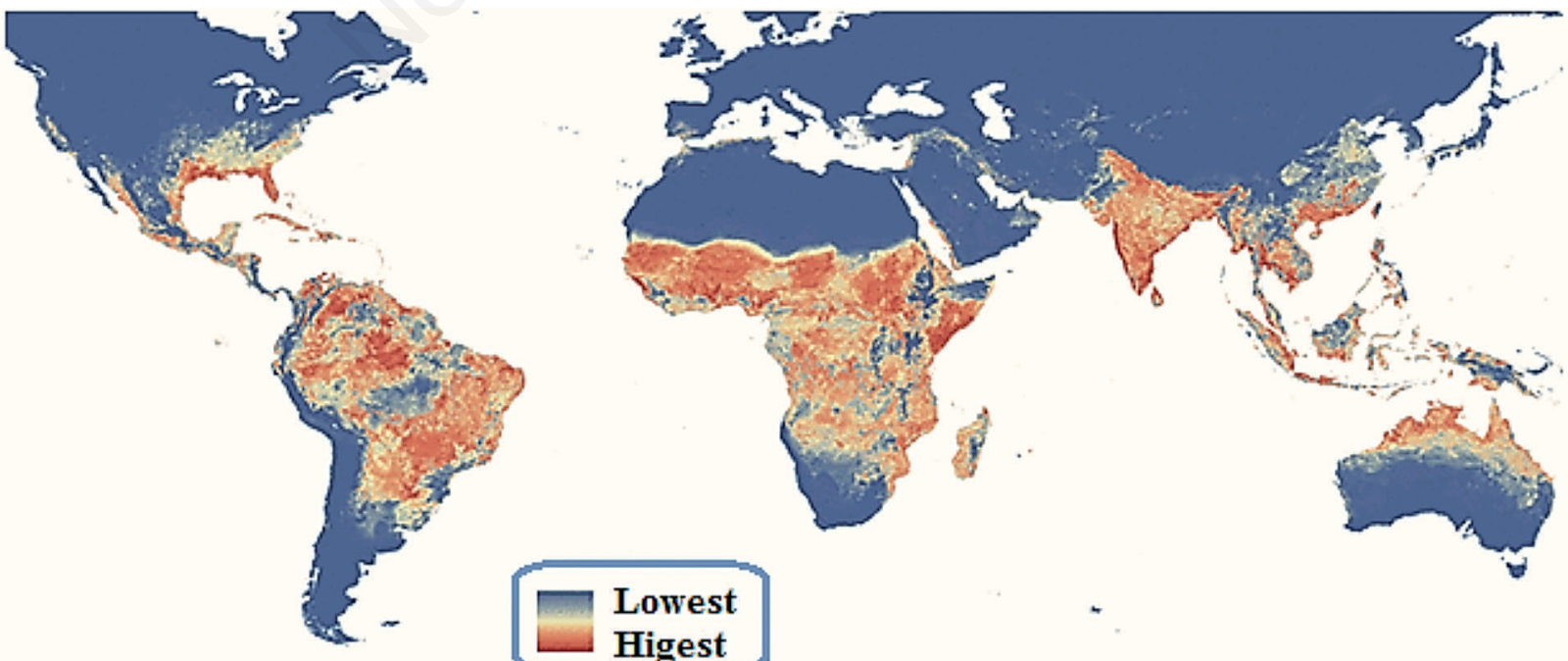

Lowest Higest

Figure 1. Global distribution of Ae. aegypti. 
present the same clinical symptoms. ZIKV is also a cause of microcephaly and other severe foetal brain defects. Zika virus has been detected in breast milk, but transmission through breastfeeding has not been yet reported.

The epidemiological importance alternative ways of transmis- sion is unknown. Sexual transmission of ZIKV has been documented in areas with no mosquito vectors (54). Although the most recent information report that Zika can remain in semen longer than in other body fluids, including vaginal fluids, urine, and blood (88), the actual time window is not clear.

Table 1. Comparison between the two main vectors for Zika virus (28).

\begin{tabular}{ll} 
Aedes aegypti & Aedes albopictus \\
Tropical and sub-tropical regions & Tropical, sub-tropical and temperate regions \\
Adapts to urban settlements & Rural and urban areas \\
\hline Feeds multiple times per cycle of eggs & Feeds once per cycles of eggs \\
Bites primarily humans & Bites primarily animals, also humans \\
\hline Bites indoors & Bites outdoors \\
\hline
\end{tabular}
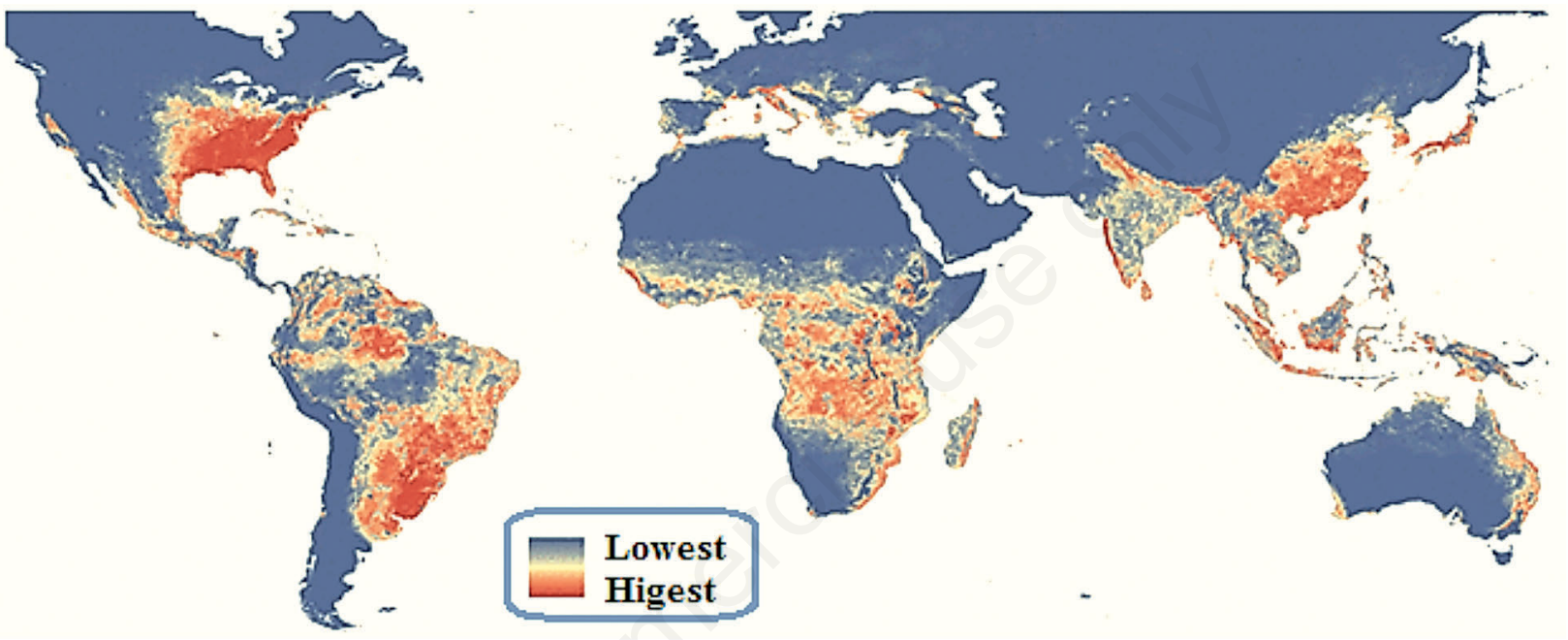

Figure 2. Global distribution of Ae. albopictus.

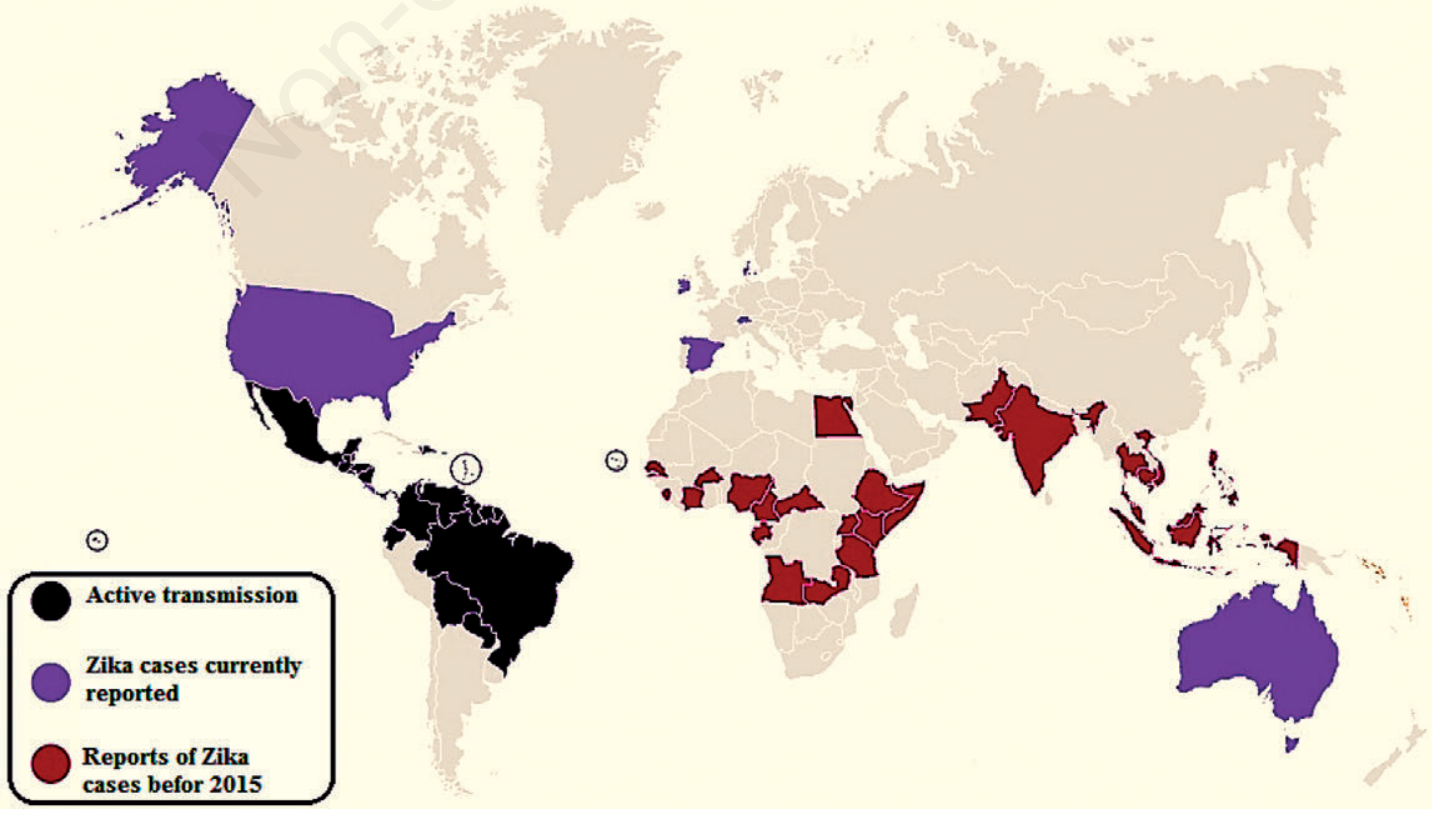

Figure 3. Spread of Zika virus. 
Recent Zika virus outbreaks and their risks led to consider transfusion of hemocomponents as another possible way of transmission, as Zika virus genome can be detected in whole blood until the 58th day after the disappearance of the symptoms, longer than for urine (26 days) and serum (3 days) (74).

During the 2013 and 2014 French Polynesia Zika outbreaks, 42 blood donators out of 1505 (3\%) presented the virus even if they did not show any symptom at the time at blood donation. Of the blood donors positive for ZIKAV, 11 (26.2\%) declared that they had a fever-like syndrome 3 to 10 days after donating $(2,68,90)$. Zika virus RNA was also detected in 2016 in asymptomatic blood donors in Puerto Rico; between April 3 - June 11, 2016, a total of $68(0.5 \%)$ presumptive viraemic donors were identified from 12,777 donations tested (64).

Although the blood donor population of Puerto Rico is not representative of the general population, the increasing prevalence of Zika virus nucleic acid among blood donors probably reflects an overall increase of incidence in the population (105).

Research reported several Flavivirus transmissions - Yellow fever, West Nile and dengue - occurred through blood transfusion, all of which have been shown to produce detectable viraemia during asymptomatic and symptomatic infections $(86,127)$.

The main problem in the prevention of transfusion transmission is the high rate of asymptomatic infections and the mild symptoms that may go unnoticed. Furthermore the incubation period for Zika virus, during which viraemia is possible, varies from 3 days to 14 days $(66,76)$.

The Brazilian media reported possible cases of transfusiontransmitted Zika virus in March 2015 and in February 2016 and a probable case of transfusion-transmitted Zika virus infection in Brazil has been recently published $(52,67)$.

Data, though limited, indicate that there is a potential risk of Zika virus transmission through blood transfusion that may have consequences to the health of recipients $(31,68)$.

Even if the scarcity of reported cases of donor-derived Zika virus infection precludes a more accurate risk assessment, the association between Zika virus infection and congenital malformations justifies measures to reduce the risk of transmission via SoHO supply $(69,150)$.

Conversely, the risk of blood donations by people infected after sexual contact with traveller returning from affected areas was shown to be extremely low in several evaluation studies conducted in Netherlands, Australia, and Frances (150).

Although there are no documented cases of Zika virus transmission through donated cells, tissues and organs, this possibility cannot be excluded due to the confirmed presence of the virus in human blood and bodily fluids. ZIKV RNA and/or protein, in fact, has been detected in urine (43), saliva (92), amniotic fluid (96) and placental tissues (77), highlighting the possibility of other types of transmission.

Alternative suspected way of transmission of ZIVK infection are those reported for other Flaviviruses. They include mucocutaneous exposure to the virus in infected blood or via monkey bite, haemodialysis, or organ transplantation (15). It is unknown whether ZIKV could be transmitted via respiratory droplets as viral RNA could occasionally be detected in nasopharyngeal swab and saliva samples (13).

\section{Symptomatology}

Zika infection is an acute exanthematous disease; for many years it circulated silently in Africa and Asia and data about cases of Zika were restricted to case reports and serological surveys; clinical manifestation was comparable to that of nonspecific viral illness.

Infection seems more frequent in women, but this may be due to the higher attendance to health services compared to men. No difference between ages was shown. Reports of child infection are limited, but they seems similar to that of adults with asymptomatic or mild symptomatic cases (60).

Zika virus infections are mainly asymptomatic (75-80\%); the symptomatic infection is similar to other arboviral infections (i.e. dengue and chikungunya). More than $95 \%$ of symptomatic infections, as described in Uganda, Yap Island and Brazil, show a mild illness characterized by maculopapular rash, which usually begins on the trunk and spreads to the arms and legs $(90 \%)$, low-grade fever $(65 \%)$, arthritis or arthralgia (65\%), non-purulent conjunctivitis $(55 \%)$, myalgia (48\%), headache $(45 \%)$ and retro-orbital pain (39\%). Less common symptoms are anorexia, vomiting, diarrhoea, dizziness, leg pain, lymphadenopathy and hypotension $(80,139)$.

Zika virus shows neurotrophism and some neurological syndrome seems associated to this infection. Guillain-Barré syndrome (GBS) an autoimmune, acute, ascending polyradiculoneuropathy and foetal microcephaly (foetal head circumference under the average for gestational age), periventricular and cortical micro-calcifications and hypoplasia cerebellar and ophthalmological manifestations following maternal infection during pregnancy have been observed $(13,55,141,142)$.

The potential association between Zika infection and neurological syndrome was first described in French Polynesia in 2013 and later in Northeast of Brazil in 2015, after observation of an increase of cases of Guillain-Barrè syndrome. The association was demonstrated in the State of Pernambuco, with the isolation of ZIKV from 7 patients affected by GBS (4). In October 2015 an increase in the number of cases of neonatal microcephaly was observed in the State of Pernambuco (there were 58 cases in a single month, far exceeding the total number of cases registered in previous years) and physicians started to investigate a connection with Zika infection in pregnant woman. The first laboratory confirmation of this came from Paraíba State with RT-PCR positivity in two pregnant women whose foetuses presented with microcephaly $(4,7)$. No cases of microcephaly were described in the French Polynesia outbreak. In 2016 ware described two cases of microcephaly in Hawaii and Slovenia: pregnant mothers were infected while in Brazil $(11,82)$.

Fatalities attributed to Zika infection are sporadic, except for foetal losses in women infected during pregnancy and infants with severe congenital ZIKV disease. Anyway, because the current epidemic is rapidly evolving, some deaths related to ZIKV have been reported. In October 2015, a 15-year-old girl previously diagnosed with sickle cell disease died with vasal occlusion, triggered by inflammation and severe splenic sequestration. On February 2016 four deaths were reported in Colombia and three in Venezuela. According to Brazilian health officials, until May 2016 three people died from complications linked to the ZIKV. At the end of February 2016 in Puerto Rico, a 70-year-old man died of complications related to severe thrombocytopenia (98).

\section{Vaccine development}

There isn't currently a ZIKV-specific vaccine available, but the many cases of Zika Virus outbreak (8) and malformation in foetuses $(18,30,70,147)$ make it necessary to develop a vaccine. At now the methods used for developing ZIKV vaccines are based on proven strategies used against other flaviviruses. However, Zika Virus carries a lot of challenges, such as pregnant women and other immunocompromised people as vaccine target, the risk of stimulating autoimmune or antibody-dependent immune responses, frequently silent infection that may delay the therapy and increase the risk of transmission, and also the different types of transmission.

In March 2016, The World Health Organization (WHO) made 
an analysis of all projects which aimed at Zika Virus interventions, including vaccines (111).

\section{Chikungunya epidemiology}

Chikungunya fever epidemics display secular, cyclical, and seasonal trends. These epidemics are characterized by explosive outbreaks interspersed by periods of disappearance ranging from several years to a few decades. Several mechanisms play a role: the human and the mosquito vector susceptibility to the virus; conditions facilitating mosquito breeding (resulting in a high vector density), ability of the vector to efficiently transmit the virus (83).

There are historical accounts of epidemics of fever, arthralgia/arthritis, and rash, resembling what is now called Chikungunya fever dating back to 1824 from India and elsewhere (61). Ancient possible cases of Chikungunya fever (CF) included a widespread epidemic of self-limited febrile illness in Africa, Caribbean, West Indies and India in the 1820s. Subsequent cases in Calcutta in 1853 and 1871 have been probably originated from Zanzibar; the most ancient reported cases of Chikungunya fever in Asia are compatible with an African origin (133). Chikungunya virus (CHIKV) was firstly detected in Central/East Africa, where is maintained in a sylvatic transmission cycle between non-human primates, small mammals (e.g. bats and monkeys) and Aedes mosquitoes (6).

During interepidemic periods, $\mathrm{CHIKV}$ is maintained in Africa via a sylvatic transmission cycle between forest-dwelling mosquitoes and non-human primates (57), involving a number of species of mosquitoes which includes Ae. aegypti, Ae. africanus, Ae. luteocephalus, and Ae. furcifer-taylori, in addition to wild primates. In Asia, conversely, the virus is maintained in cycles between $A e$. aegypti or, most recently, Ae. albopictus and humans. Venereal transmission of CHIKV in $A$. aegypti, with the identification of male mosquitoes positive for CHIKV, and transovarial transmission has been reported (108).

Urban chikungunya fever outbreaks are initiated by spillover infection of humans from enzootic African transmission cycles. The first identified outbreak of Chikungunya, with an incidence estimated at 23\%, was reported from July 1952 to March 1953 in the Southern Province of the currently Tanzania (120). The virus was first isolated from a febrile patient by Ross in 1953 and described by Robinson and Lumsden in 1955 during a dengue epidemic that occurred in the Newala and Masisi districts $(22,121)$ (along the border between Mozambique and Tanganyika). The specific region of focus was the Makonde Plateau.

Since its discovery, numerous Chikungunya re-emergences have been documented. Currently, the Chikungunya virus has been identified in over 60 countries (Figure 4) (146). The risk of importation of CHIKV into new areas is ever present because of the high attack rates associated with the recurring epidemics, the high levels of viraemia in infected humans, and the worldwide distribution of the vectors responsible for transmitting CHIKV.

\section{Virus}

Phylogenetic studies revealed the existence of two major enzootic CHIKV lineages in Africa: Western, and East/Central/South African (ECSA) (14). In addition to that, Asian genotypes also exist with distinct antigenic and genotypic characteristics (53). The ECSA and Asian strains were calculated to have diverged within the last 150 years, with the Asian clade splitting into an extinct Indian lineage and the currently circulating Southeast Asian strains. Recent Indian Ocean isolates form a monophyletic lineage descending from the ECSA clade (26). This last lineage originated from a change in the viral genotype which affected infectivity for Ae. albopictus during the 2005 Indian Ocean epidemic (114). While laboratory studies had found that Ae. albopictus is a competent vector for CHIKV (138), it had not been implicated as a major vector in CHIKV epidemics previous to 2005.

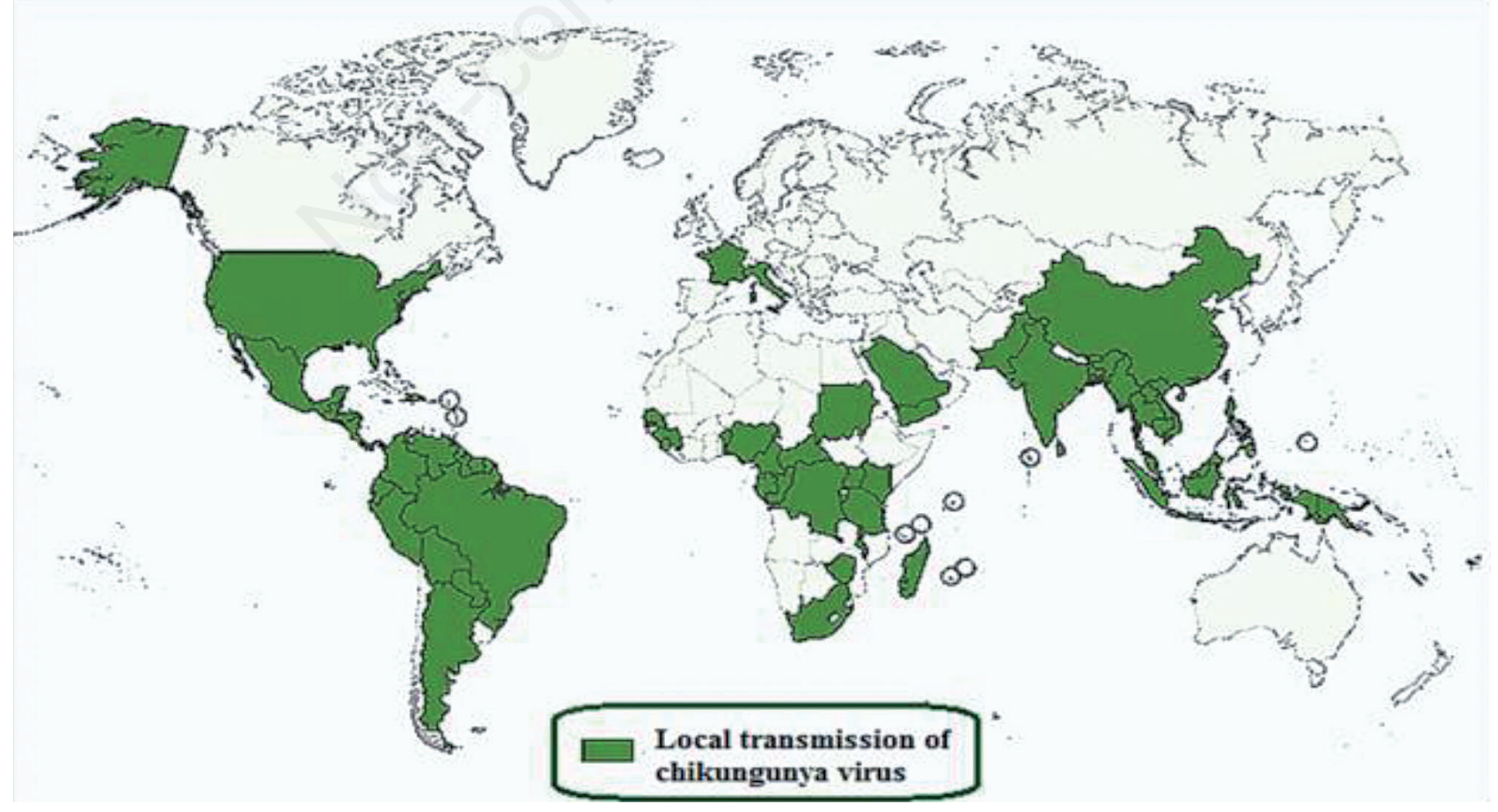

Figure 4. Countries where chikungunya cases have been reported as of April 22, 2016. 
RNA viruses great capacity for genetic variation has long been known and is due to the inability of the viral RNA-dependent RNA polymerase $(\mathrm{RdRp})$ to error correct. The frequent nucleotide misincorporation during replication gives rise to heterogeneous populations of viral RNAs which take the name of mutant swarms, typical of alphaviruses like CHIKV. Most mutant genomes are detrimental and removed from the swarm via purifying negative selection, while positive selection of a fit phenotype results in increased abundance of a genotype. A dynamic mutation-selection balance therefore determines the size and genetic diversity of a mutant swarm.

This mechanism often leads to the evolution of geographically isolated lineages, occasionally changing the vector or host specificity. The populations thus generated may contain a variant that is selected due to a competitive advantage, such as the ability to replicate to higher titres in a mosquito or vertebrate host, or to extend its host range. Such was the case for CHIKV, where a single mutation, alanine to valine at position 226 in the E1 envelope glycoprotein gene (A226V E1), facilitated CHIKV replication in and therefore transmission by the highly anthropophilic Ae. albopictus, thus originating the ECSA Indian Ocean lineage (IOL) genotype (124). The E1-226V variant was more efficiently transmitted by $A$. albopictus (137), with a roughly 40 -fold more efficient initial infection of midgut epithelial cells. The selection of the E1-226V variant occurs at the initial infection of the midgut of $A$. albopictus, leading to a higher viral dissemination and transmission of the IOL genotype by this mosquito. In addition to facilitating the explosive Indian Ocean epidemic, this mutation also allowed substantial geographic expansion of CHIKV throughout sub-Saharan Africa, Southeast Asia, and into Europe (133). Although the A226V E1 mutation itself modulates CHIKV infectivity and transmission by Ae. albopictus, this mutation is limited to CHIKV ECSA strains, and other mutations in E1 and E2 have been found to block the A226V E1-mediated adaptation to Ae. albopictus (137).

The A226V E1 mutation has arisen independently at least four times in response to a requirement of transmission by Ae. albopictus (i.e., in areas without Ae. aegypti or areas populated by Ae. albopictus and Ae. aegypti) (26). The result is that Ae. albopictus has become a major CHIKV vector.

Following the detection of the A. albopictus-adaptive A226V substitution, the impact of CHIKV genetics on urban vector infection and transmission has received considerable study. The distinction in vector specificity for Ae. aegypti by CHIKV is determined by genetic sequences in the structural genes (17), however the impact of single genetic loci in both regions still remains to be characterized.

Further phylogenetic/reverse genetic studies of IOL CHIKV revealed a series of four independently acquired second-step, $A$. albopictus-adaptive mutations, all involving E2 substitutions, one of which relying also on a synergistic effect with an E3 substitution (136). Each of these mutations increases initial infection of the mosquito midgut and has little or no effect on infection of $A$. aegypti. Furthermore, at least one combination of these mutations leads to a more efficient $A$. albopictus infection than that of any natural CHIKV strain studied to date, suggesting further vectoradaptive evolution and even more efficient circulation in regions where this mosquito is abundant. Structural modelling of these $A$. albopictus-adaptive envelope glycoprotein substitutions suggests that they alter the entry process in endosomes by affecting conformational changes required for E1 fusion with endosomes rather than directly affecting receptor binding (17).

An increased vector range further increases the risk of importing CHIKV into new ecological niches through infected travellers returning from destinations experiencing CHIKV epidemics. It has been predicted that combinations of these additional adaptive mutations would evolve in endemic strains in India and Southeast Asia, mediating even greater fitness in Ae. albopictus, and that these strains would spread globally. Furthermore, an outbreak in 2013 involving the Asian lineage of CHIKV on Yap Island involved Ae. hensilli (123). Virus detection in one pool of male mosquitoes suggested vertical transmission.

\section{Vectors}

CHIKV circulates in two distinct transmission cycles: enzootic transmission among nonhuman primates and perhaps other vertebrates by arboreal Aedes spp. mosquitoes in sub-Saharan African sylvatic foci, and urban transmission among humans by $A$. aegypti and/or A. albopictus.

The urbanization of CHIKV, with epidemics occurring in peridomestic settings following the emergence of enzootic strains, coincides with the involvement of anthropophilic mosquitoes: $A$. (Stegomyia) aegypti and A. (Stegomyia) albopictus (Skuse), favoring inter-human transmission. Phylogenetic studies indicate that the establishment of the urban transmission cycle has occurred on multiple occasions from strains circulating in the eastern half of Africa in nonhuman primate hosts.

Aedes aegypti and $A$. albopictus have both spread beyond their native ranges via commercial trade and desiccation-resistant eggs (56).

Aedes aegypti, originated in African forests and is today present in most tropical countries (33). In Africa, A. aegypti is present in two genetic forms: the dark and sylvatic A. aegypti formosus, found in forested habitats and using tree holes as larval development sites; and the pale and domestic A. aegypti aegypti, which is widespread in the tropics and subtropics and uses artificial larval habitats mainly in urban environments (Figures 5 and 6).

Aedes aegypti aegypti originated from the forest-dwelling formosus form, which may have spread from tropical African forests to North Africa where it probably became domesticated under pressure to use artificial water storage containers as larval habitats. These mosquitoes progressively differentiated into domesticated populations known as A. aegypti aegypti. Human trading activities later introduced this subspecies globally throughout the most of the tropics and subtropics: the New World via the African slave trade from the 15th to 19th centuries, Asia in the 18th and 19th centuries, and the Pacific islands with troop movements during World War II.

Aedes aegypti can exist sympatrically with A. albopictus and also often shares larval habitats.

Aedes albopictus, originally described by Skuse in Calcutta, India in 1894 originated in forests of Southeast Asia (47), but is now is commonly found in peri-urban, rural and forested areas on five continents. Aedes albopictus has no particular ecological specialization, colonizing both temperate and tropical regions. Two types of populations are described: temperate populations imported to the U.S. from Japan and then from the U.S. to Europe (79), where they are now established in 20 European countries; these temperate populations are characterized by diapausing, cold-resistant eggs.

Ae. albopictus easily adapts in both the rural and urban environments, that makes it an ideal viral vector. Besides, the mosquito's eggs are highly resistant even in dry periods, giving rise to larvae in rainy season. All of these characters make Ae. albopictus, an important vector for spreading this disease. Ae. albopictus is geographically distributed in Asia, Europe, Middle East and America.

Since the 1980s, Ae. albopictus has invaded and become established in many parts of the world, including the Americas and Europe. The range expansion, primarily due to human activities related to global commerce, together with viral evolution described below, has been a major contributory factor to the spread of CHIKV. 


\section{Distribution}

Chikungunya virus (CHIKV) was first documented during an outbreak in modern-day Tanzania between 1952 and 1953 (116). The virus subsequently caused large outbreaks in the 1960s and 1970 s but then was infrequently observed during the next 30 years. In 2004, 2 outbreaks occurred in coastal Kenya (125) to the islands of the Indian Ocean, India, Southeast Asia, Europe, the Western Pacific islands, and finally, in 2013, the Americas.

In 2004, CHIKV belonging to the ECSA lineage emerged from Lamu and Mombasa in coastal Kenya (59) and spread to Comoros, beginning a decade-long cycle of re-emergence and expansion as the virus moved from Africa to the islands of the Indian Ocean including La Réunion.

During 2005-2006, the virus spread to neighbouring Indian Ocean islands including Mayotte, Mauritius and Madagascar, where CHIKV E1-A226V was mainly transmitted by A. albopictus (113). Subsequently, the CHIKV IOL was introduced to India (153) and the surrounding islands, Sri Lanka (65) and the Maldives. In Africa, the CHIKV E1-226V variant was also impli- cated outbreaks in Cameroon (107), Gabon (106) and Congo (84). This variant also caused the first European CHIKV outbreak in Italy in 2007 (115). Since 2008, IOL CHIKV strains were also imported into Southeast Asia: Malaysia (119), Singapore (95), Thailand (131), China (152), Cambodia (25) and Bhutan (143).

In September 2010, autochthonous cases of CHIKV were reported in southeast of France (42), again with A. albopictus as the vector. In Southeast France, this species appears to behave differently compared to its tropical counterpart, as it efficiently transmits the E1-226A IOL variant detected in local circulation. Aedes albopictus has been found in in 18 French departments as well as 19 other countries in Europe (135).

Prior to December 2013, CHIKV transmission was not documented in the Americas, despite numerous introductions and the presence of conditions that are apparently suitable for its establishment (71). In October 2013, two laboratory-confirmed, autochthonous CHIKV cases were detected in the French territory of Saint Martin Island, in the Caribbean Sea (102). Surprisingly, the CHIKV strain isolated belonged to the Asian genotype rather than

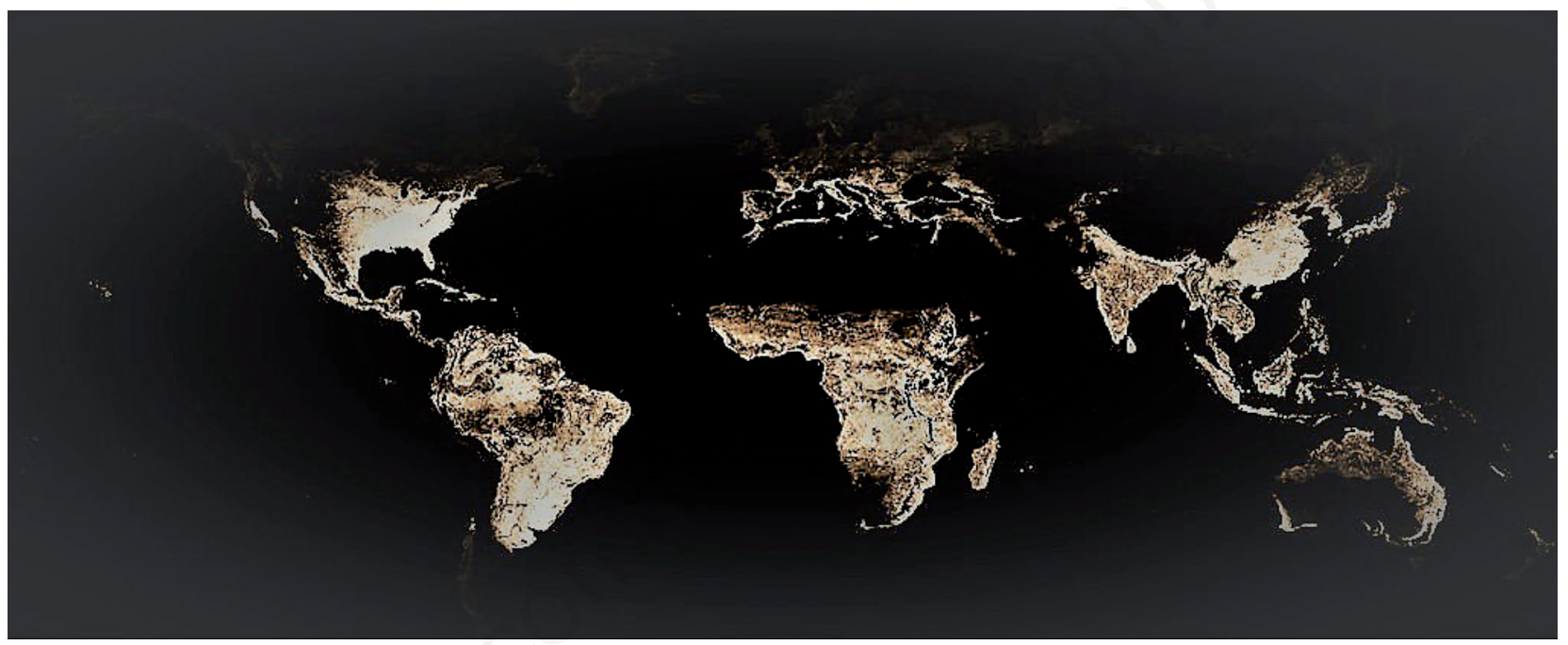

Figure 5. Global distribution of Ae.albopictus.

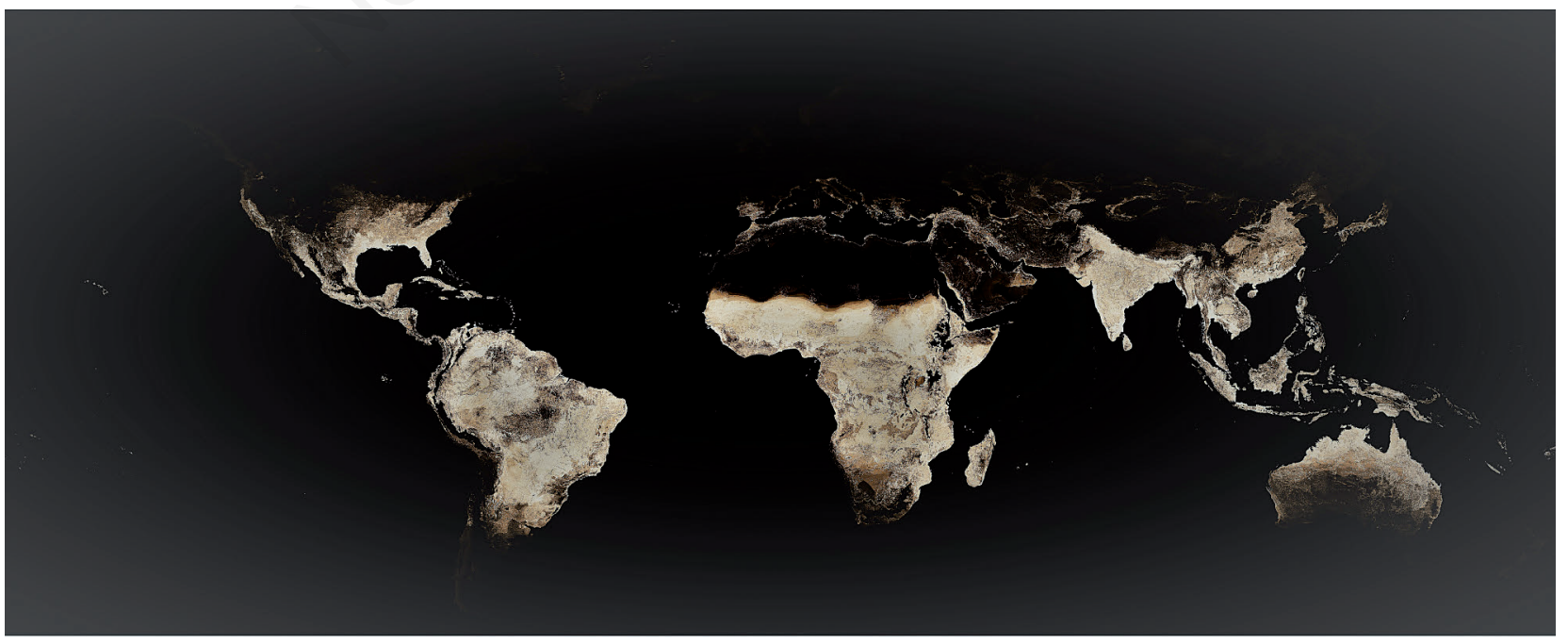

Figure 6. Global distribution of Ae.aegypti. 
the IOL that emerged in 2004 in the Indian Ocean Basin and Asia. The only vector implicated in St. Martin, where A. albopictus has not been established, was $A$. aegypti. Subsequently, CHIKV progressively spread throughout most of the Caribbean, and into Central and South America where human populations are mostly naïve to CHIKV (71).

American populations of $A$. aegypti and A. albopictus are susceptible to both ECSA/IOL and Asian genotypes of CHIKV with higher susceptibility observed for A. aegypti and the Asian CHIKV genotype, or A. albopictus and the ECSA/IOL genotype (144).

\section{Reported cases}

After the outbreak in Tanzania in 1952-1953, epidemics were reported in South Africa in 1956 and in 1975-1977; in Zimbabwe in 1957, 1961-1962, and 1971; in the Democratic Republic of Congo in 1958 and 1960. Chikungunya fever was detected in Zambia in 1959 and in Senegal in 1960. Outbreaks occurred in Uganda in 1961-1962 and 1968; in Nigeria CHIKV cases were reported in 1964, 1969, 1974; in Angola and in the Central African Republic in 1970-1971 and in 1978-1979, respectively $(20,58,109)$.

In Asia, the first CHIKV epidemic was documented in 1958 in Bangkok, Thailand (45) followed by numerous documented outbreaks in the Philippines, Cambodia, Vietnam, Laos, Myanmar, Malaysia and Indonesia (129).

The epidemic reported in Bangkok in 1958, was the first significant urban outbreak of Chikungunya virus in Asia. CHIKV was isolated from blood specimens (collected from patients during the epidemic of dengue fever and a dengue haemorrhagic fever). There are biennial epidemic surges: in 1958, 1960, 1962 and 1964 there were 2297, 1660, 4187 and 5358 patients hospitalized in Bangkok, respectively (45).

Other important outbreaks were reported from 1963 through 1973 in India, where the vectors are widely prevalent during the post monsoon season (16).

CHIKV was first detected in West Bengal in 1963 and Calcutta experienced a concurrent epidemic of Dengue and Chikungunya between 1963 and 1965 (122). In 1964, in the Southern Indian districts of Chennai and Vellore there were large outbreaks with $>400,000$ cases (10).

Ten years later, in 1973, the CHIK virus was also identified in Solapur (Maharashtra Indian district). Comparison of two Asian Chikungunya virus strains that were isolated 10 years apart showed $99.4 \%$ identity (158).

In 1969 CHIKV fever was reported in Sri Lanka. After 1973, no major outbreaks were registered in Asia, rather sporadic cases.

Localized outbreaks have occurred in the Philippines and Indonesia in the 1980s and in Malaysia in the 1990s. In Malaysia, the first outbreak was identified in 1998 (119).

Phylogenetic analysis of envelope's glycoprotein, E1, indicates three lineages with distinct genotypic and antigenic characteristics: the East-Central-South African genotype (ECSA), the Asian genotype and the West African genotype reflecting the initial geographical distribution of the virus (128).

In Africa, in addition to the historical outbreaks starting in the 1960 s, a resurgence of CHIKV has been observed since the end of the twentieth century.

Since 2000s, outbreaks have become more frequent and emerging genetic evidence suggests possible mechanisms for evolutionary adaptation of the virus to the mosquito vector (6).

In the Democratic Republic of the Congo, resurgence of the disease after nearly 40 years was observed in 1999-2000 during an urban epidemic in Kinshasa, which affected about 50000 persons (94).

Prior of 2004, CHIKV was endemic in Africa, Sud-Est Asia and India. The situation worsened when the CHIKV re-emerged in
Kenya in 2004 (125). Kenya experienced two major outbreaks. The first outbreak was reported in Lamu Island (13,500 cases estimated). A few months following, a second outbreak occurred in the city of Mombasa. Previous outbreaks in Africa had rarely led to spread of the disease outside of continental, whereas this time, it gave origin to a decade-long cycle of re-emergence and expansion as the virus moved in the 2000s to the Islands of the Indian Ocean, Europe, the Western Pacific Islands and finally, in the Americas.

By January 2005, a CHIK fever was detected in the Union of the Comoros. Approximately $60 \%$ of the population may have been infected with CHIKV in Grande Comore (124), suggesting that over 215,000 infections had occurred. Then the epidemic spread to other Islands. Seychelles reported 8800 suspected cases ( $10 \%$ of the population) in January-February 2005.

The most severe CF outbreak ever recorded at the time, was reported from March 2005 to May 2006 in the Réunion Island when one-third of the population was infected $(266,000$ resident cases/ 770,000 inhabitants) (124) with an overall attack rate of $35 \%$. After a period of lower transmission during the winter season (June to September 2005), with the arrival of the Southern Hemisphere summer, the rainy season gave rise to a renewed epidemic circulation of the virus (126). The peaked incidence was about 25,000 cases per week and 3,500 per daily in early 2006 . Outbreaks occurred in other nearby Islands. Madagascar and Mayotte reported outbreaks in January 2006.. Mauritius reported about 13,500 suspected cases from February to May 2006; CHIKV outbreak in the Maldives started in December 2006 and lasted for three months. Nearly 11,000 suspected cases were registered (113). Cases, although lesser in number, were also reported in 2007.

It was the first time, during an outbreak, neurological manifestations, foetal infections, and mortality (237 deaths) were associated with CHIKV (23). During this outbreak, was observed an elevate death-rate and a case-fatality ratio of about 1 in 1000. A similar case-fatality ratio was observed following the outbreak in Port Blair, capital city of the Union Territory of Andaman and Nicobar Islands, India, in 2006 (158). Prevalence of the disease on the Islands as well as the prevalence among pregnant women were of special interest. In July of 2006, the prevalence rate in the Réunion was found to be $34.3 \%$, which was determined by a regional surveillance-system managed by the Cellule Interrégionale d'Epidémiologie (CIRE) (40).

A large number of imported cases in Europe was associated with this outbreak. Several imported cases in France coinciding with the outbreak in La Réunion. In 2010 were reported 37 cases: 32 confirmed, 2 autochthonous (135). CHIKV diseases autochthonous transmission was reported in south-east of France, in the region of Provence-Alpes-Cote d'Azur with two established cases in September 2010. One French traveller acquired CHIKV in the Réunion Island, another in Benin, India. Experimental infections with the 2010 strain detected in France have shown that the local Aedes albopictus mosquitos in southern France exhibited a high efficiency for CHIKV transmission. A. albopictus was the main suspected vector species in the Réunion, Mauritius and Seychelles. Studies revealed that the CHIKV involved in the Réunion outbreak had a single point mutation in E1 (E1- A226V) that increased infectivity in A. albopictus (124).

Re-emergence was also documented in Indonesia between January 2001 and April 2007 (15,207 cases), with a peak observed in 2003 (69).

CHIKV resurfaced in India, affecting several states: the outbreak started in December 2005 from the coastal regions of Andrah Pradesh and Karnataka (153) and it involved also Maharashtra (Western region) and Orissa (Eastern Central region) in 2006. It was estimated than more of 1.3 million people were affected across 
150 districts of 8 states. In particular, in Orissa, CHIK F was detected in 13 of the country's 30 districts and it spread to a wider geographic zone in a short period of time. The persistent number of cases in India in 2006-2007 and the high attack rate were probably attributable to a large amount of immunologically naive people, who help sustain viral transmission. Several other countries in South-East Asia were also affected. The majority of cases was reported from September to November (late monsoon season). The social and economic impact of Chikungunya fever has been considerable, especially in India. Phylogenetic analyses showed the strain was closely related to the Réunion Island strain while outbreaks reported in India in 1960s and 1970s were related to the Asian genotype.

CHIKV in India served as the source of viral introduction to Italy. In 2007 the virus caused the first autochthonous epidemic outbreak in Europe, in the north-east of Italy, with 292 suspected Chikungunya fever and 197 confirmed cases (115). The majority of cases were reported from two neighbouring small villages separated by a river. The presumed index case come from a chikungunya-affected area in Kerala, India, in June 2007. The virus isolated from humans and $A$. albopictus mosquitoes was closely related to the ECSA genotype and had the E1-glycoprotein mutation.

Since August 2008, infections were also reported from Singapore, Malaysia, Thailand and Australia. CHIK fever has reemerged again in Thailand with several thousands of reported cases from at least 47 provinces. More than 42,000 cases of the disease were reported in southern Thailand, including the popular tourist destination of Phuket (131).

In 2010, the virus continued to cause illness in India, Indonesia, Myanmar, Thailand, and the Maldives; it also has resurged in La Réunion. In the same year, imported cases also were identified in Taiwan, France, and the United States. These cases were infected viraemic travellers returning from Indonesia, La Réunion, and India, respectively $(42,71)$.

Chikungunya virus travelled from its historic homes: Africa and Asia/Southeast Asia, to arrive and spread pandemically in the Americas, threatening permanent establishment (71).

There were nine imported CHIK cases reported in the French territories, in the Americas since 2006: three in Martinique, three in Guadeloupe and three in Guyana. None of these travel-related cases have led to local transmission, but these cases documented an on-going risk for the introduction and possible sustained transmission of CHIKV in the Americas.

From 2006 through 2010, among travellers returning to the United States, 106 CHIKV cases (probable and laboratory-confirmed) were detected (71). From 2010 through 2013, 115 laboratory-confirmed chikungunya virus infections were identified among travellers returning to United States. Among 55 cases with known travel history, 53 reported travel to Asia and 2 to Africa. No locally-acquired infections were identified.

In the Philippines, the disease has re-emerged in 2011 affecting initially few provinces and spreading all throughout the country over the last 3 years. In 2012 and 2013, cases of Chikungunya fever have been confirmed in 43 of the country's 80 provinces and outbreaks have been reported (129).

In late 2013, the first evidence of autochthonous CHIKV infection was reported in the Carribean Island of Saint Martin (French Antilles), It was the first instance of autochthonous transmissions of CHIKV in the Americas in the past century. The confirmed cases were 66 and suspected cases of around 181 in December 2013 (73). Since 2013, local transmission has been confirmed in over 43 countries and territories in the WHO Region of the Americas. Since CHIK fever was first reported in St.Martin, the virus has spread to 45 territories in North, Central and South
America causing $>2.9$ million suspected cases and 296 deaths as of late July 2016. Particularly high incidences were reported in areas such Dominican Republic (41\%) and Suriname (90\%).

In the Island of St. Martin was reported the Asian lineage of the CHIKV strain. The Caribbean strain was nearly identical to strains circulating in the Philippines and China in 2012. In an immunologically naive population, CHIKV spread rapidly throughout the Caribbean region and beyond to most countries in the Western Hemisphere, including 11 autochthonous cases reported in Florida, USA, in September 2014. Autochthonous transmission has been detected in 34 countries and territories of the America (27 in the Caribbean, 3 in Central America, 2 in South America and 1 in North America). More than 1.2 million autochthonous cases were reported to Pan American Health Organization (PAHO) in the Americas for the period 2013-2014. Near the end of 2013, CHIKV was introduced to the Caribbean and resulted in a large outbreak that has now spread to Mexico and many countries in Centraland South America. By January 2014, numerous cases had been confirmed in five countries: St. Martin, St. Barthelemy, Martinique, Guadeloupe, and the British Virgin Islands. A viral isolate from the Virgin Islands was collected and sequenced by Centre for Disease Control (CDC). The strain's origin was Asian (67).

In Brazil indigenous transmission were registered in Amapa and Bahia States, even during the period of low rainfall, exposing the whole country to the risk of virus spreading (19).

There were cases in 15 atolls of the Caribbean in April 2014 and the total number of cases reached 35,000 (23). Puerto Rico and Samoa have also reported locally acquired cases.

By the start of May 2014, there were more than 4100 probable cases, and 31,000 suspected cases spanning 14 countries, including French Guiana, the only non-Island nation with at least one reported case. The Caribbean Public Health Agency declared a Caribbean-wide epidemic of the virus.

In March 2015, the US CDC reported that CHIKV infection had been identified in 44 countries or territories in the Caribbean, North, Central and South America with more than 1.3 million suspected cases and over 28,000 confirmed cases (99). The Isle of Saint Martin reported the highest incidence (115 cases/1000 population). Martinique (76 per 1000), Saint Barthelemy (74/1000) and Guadeloupe (52/1000) also reported high incidences of CHIKV infection. In late 2015 in the city of Dakar, Senegal, and the state of Punjab, India, significant outbreaks occurred. In the Americas in 2015, 693489 suspected cases and 37480 confirmed cases of chikungunya were reported to the Pan American Health Organization (PAHO).

In South America, by January 2015, Colombia, saw their first local transmission of CHIKV and the country accounts for 70 percent of CHIKV cases in 2015 (356,254 confirmed or suspected cases in 2015) (12).

\section{Transmission}

Chikungunya virus is usually transmitted to humans by the bite of an infected female mosquito. The mosquito species involved found in many areas of the world - are Aedes aegypti and Aedes albopictus. The risk of transmission to a second person is highest when the patient is viraemic - usually during the first $2 / 6$ days of illness.

During the 2005-2006 outbreak on Réunion Island, neonatal cases observation suggested that also a vertical transmission during pregnancy is possible. A recent study showed that, among 151 infected women, 118 were viraemia negative at delivery and none of the newborns showed any damage. Among 33 viraemic women at delivery, 16 gave birth to newborns who presented neonatal Chikungunya. Trans placental transmission is suspected but the 
pathogenic mechanism remains unknown. It has also been shown that caesarean section did not prevent transmission. In a second study, 38 neonatal cases were studied retrospectively. All of them developed symptoms between Day 3 and Day 7 (mean, Day 4). Mean interval between the onset in mothers and in the babies was five days. Frequent and prominent signs in the neonates were rashes $(82 \%)$, fever (79\%) and peripheral oedema (58\%) (148).

Pregnant women present symptoms and outcomes similar to those of other people, and most CHIKV infections that occur during pregnancy will not result in the virus being transmitted to the foetus. However, when intrapartum transmission does occur, especially when a woman is viraemic in the last trimester or at the time of deliver (148), it can result in complications for the baby, including neurological disease, haemorrhagic symptoms, and myocardial disease. There are also rare reports of spontaneous abortions after maternal CHIKV infection. Regarding the transmission through breastfeeding, Chikungunya virus has not been found in breast milk.

Chikungunya virus RNA can be detected in semen (93); although the detection of Chikungunya virus in semen can lead to a possible sexual transmission, no case has been documented. Furthermore, the virus could be spread through blood transfusion and organ donation, therefore, people living in high incidence areas of virus transmission should be excluded from blood donation as long as the transmission is on-going (148).

\section{Vaccine development}

Several animal models of CHIKF have been described. The cynomolgus macaque (Macaca fascicularis) model reflects human disease most accurately (114), and therefore it is commonly used to study pathogenesis and vaccine efficacy.

When evaluating CHIKF vaccines, both humoral and cellular immunity have been assessed. For protection from disease, human and animal studies suggest that $\mathrm{nAb}$ are critical.

There are currently over 16 CHIKF vaccine candidates in preclinical and clinical development, each approach using a different strategy, with consequent varied safety and immunogenicity tradeoffs. Because these candidates are in different stages of development, the immunogenicity assays and animal models that are used vary widely, therefore making comparisons difficult.

\section{Inactivated and subunit vaccines}

Protein subunits and inactivated vaccines and are traditionally considered the safest platforms.

Inactivation is achieved irradiating cultured virus or exposing it to formaldehyde; this is then followed by purification to remove the chemical. This approach was first used for CHIKV in the 1970s.

The costs of manufacturing at high bio-containment and ensuring the total inactivation of the infectious virus are the main concerns with this approach (27). However, the developmental pathway for inactivated vaccines is straightforward, does not require genetic manipulation of the virus, and has yielded successful vaccines for several viral diseases.

While biosafety level 3 measures are necessary for the inactivation of wtCHIKV, recombinant proteins synthesis does not require bio-containment. The favourable safety and manufacturing features of recombinant protein subunit vaccines has prompted the development of a number of CHIKF vaccine candidates using this platform.

One method uses either a combination of adjuvant E1 and E2 envelope proteins or E2 and adjuvant alone (21). This approach, though, generates short-lived immunity, requires multiple doses, and provides only partial protection from viraemia in $\mathrm{BALB} / \mathrm{c}$ mice. Additional efficacy studies in other animal models are required to better evaluate these candidates.

\section{Virus-like particles}

Virus-like particles (VLP) tend to be more immunogenic than inactivated or subunit vaccines while remaining equally safe. Several approaches are used to produce self-assembling VLPs, all of which require expression of the complete CHIKV structural protein open reading frame (ORF). One method uses a baculovirus to generate large amounts of protein. Another requires cells to be transfected with nucleic acids encoding these genes, which secrete self-assembling VLPs into the cell culture supernatant (27).

\section{Live-attenuated vaccines}

The first live-attenuated vaccine progressed the furthest into clinical trials. This vaccine was created from a CHIKV isolate from Thailand and passaged in human lung cells (MRC-5) to generate an attenuated virus. This resulted in a virus that produced smaller plaques compared to the parental virus. In humans, this vaccine proved to be highly immunogenic, but also caused arthralgia in some of the vaccines $(27,72)$.

Although 10 nucleotide differences were observed between the attenuated strain and its parent, the actual attenuation in caused by only 2 non-synonymous mutations in the E2 gene, and reversions at these positions occurred in human volunteers and mice. This proves the need to stabilize the attenuation mechanism of this vaccine before additional development.

\section{Live virus-vectored vaccines}

Another strategy in CHIKF vaccine development is the use of vaccine vectors, such as vesicular stomatitis viruses (VSV) and measles virus (MV), that have been used to generate vaccine candidates for other diseases. In this approach, the structural CHIKV genes are inserted into the vector's genome to produce a virus that, in $\mathrm{MV}$, initiates expression of CHIKV structural proteins upon infection or, in VSV, contains CHIKV structural proteins embedded in the virion (112).

\section{Commercial and regulatory challenges}

Several CHIKF vaccine candidates appear highly promising for protection against $\mathrm{CHIKV}$. Because CHIKV is antigenically conserved, with extensive cross-reactions of antibodies, including $\mathrm{nAb}$, and there is no evidence of reinfection (32), a single vaccine could probably provide worldwide protection. However, commercial and regulatory challenges for bringing a vaccine to market are to be taken into consideration.

Despite gaining international attention since it emerged in 2004, and especially since it spread to Europe in 2007 and to the Americas in 2013, CHIKV is rarely diagnosed during interepidemic periods lasting decades. This may lead to a return to obscurity after outbreaks subside with increasing herd immunity, with a consequent decline of the demand and the potential market for a vaccine.

\section{References}

1. Alera MT, Hermann L, Tac-An IA, et al. Zika virus infection, Philippines, 2012. Emerg Infect Dis 2015;21:722-4.

2. Aubry M, Finke J, Teissier A, et al. Seroprevalence of arboviruses among blood donors in French Polynesia, 20112013. Int J Infect Dis 2015;41:11-2.

3. Besnard M, Lastere S, Teissier A, et al. Evidence of perinatal transmission of Zika virus, French Polynesia, December 2013 and February 2014. Euro Surveill 2014;19:207-51. 
4. Brito CA, Cordeiro MT. One year after the Zika virus outbreak in Brazil: from hypotheses to evidence. Rev Soc Bras Med Trop 2016;49:537-43.

5. Buathong R, Hermann L, Thaisomboonsuk B, et al. Detection of Zika virus infection in Thailand, 2012-2014. Am J Trop Med Hyg 2015;93:380-3.

6. Burt FJ, Rolph MS, Rulli NE, et al. Chikungunya: a re-emerging virus. Lancet 2012;379:662-71.

7. Calvet G, Aguiar RS, Melo ASO, et al. Detection and sequencing of Zika virus from amniotic fluid of fetuses with microcephaly in Brazil: a case study. Lancet Infect Dis 2016;16:653-60.

8. Campos GS, Bandeira AC, Sardi SI. Zika virus outbreak, Bahia, Brazil. Emerg Infect Dis 2015;21:1885-6.

9. Cao-Lormeau VM, Roche C, Teissier A, et al. Zika virus, French Polynesia, South Pacific, 2013. Emerg Infect Dis 2014;20:1085-6.

10. Carey DE, Myers RM, DeRanitz CN, et al. Chikungunya epidemic at Vellore, South India, including observations on concurrent dengue. Trans R Soc Trop Med Hyg 1969;63:434-45.

11. Centers for Disease Control and Prevention (CDC). DOH News Release: Hawaii Department of Health Receives Confirmation of Zika Infection in Baby Born with Microcephaly. 2016;3:2-3.

12. Centre for Infectious Disease and Policy (CIDRAP) Website. Available from: www.cidrap.umn.edu

13. Chan JF, Choi GK, Yip CC, et al. Zika fever and congenital Zika syndrome: an unexpected emerging arboviral disease. J Infect 2016;72:507-24.

14. Chen KC, Kam YW, Lin RT, et al. Comparative analysis of the genome sequences and replication profiles of Chikungunya virus isolates within the East, Central and South African (ECSA) lineage. Virol J 2013;10:1-8.

15. Chen LH, Wilson ME. Transmission of dengue virus without amosquito vector: nosocomial mucocutaneous transmission and other routes of transmission. Clin Infect Dis 2004;39:e56-60.

16. Chhabra M, Mittal V, Bhattacharya D, et al. Chikungunya fever: a re-emerging viral infection. Indian J Med Microbiol 2008;26:5-12.

17. Coffey LL, Failloux AB, Weaver SC. Chikungunya virus-vector interactions. Viruses 2014;6:4628-63.

18. Cugola FR, Fernandes IR, Russo FB, et al. The Brazilian Zika virus strain causes birth defects in experimental models. Nature 2016;534:267-71.

19. da Silva Azevedo R, Oliveira CS, da Costa Vasconcelos PF. Chikungunya risk for Brazil. Rev Saude Publica 2015;49:58.

20. Desdouits M, Kamgang B, Berthet N, et al. Genetic characterization of chikungunya virus in the Central African Republic. Infect Genet Evol 2015;33:25-31.

21. DeZure AD, Berkowitz NM, Graham BS, Ledgerwood JE. Whole-inactivated and virus-like particle vaccine strategies for chikungunya virus. J Infect Dis 2016;214:S497-9.

22. Diallo M, Thonnon J, Traore-Lamizana M, et al. Vectors of Chikungunya virus in Senegal: current data and transmission cycles. Am J Trop Med Hyg 1999;60:281-6.

23. Diop D, Meseznikov G, Sanicas M. Chikungunya outbreaks from 2000 to 2015: a review. MOJ Public Health 2015;2:00043.

24. Duffy MR, Chen TH, Hancock WT, et al. Zika virus outbreak on Yap Island, Federated States of Micronesia. N Engl J Med 2009;360:2536-43.

25. Duong V, Andries AC, Ngan C, et al. Reemergence of chikungunya virus in Cambodia. Emerg Infect Dis 2012;18:2066-9.

26. Enserink M. Infectious diseases. Massive outbreak draws fresh attention to little-known virus. Science 2006;311:1085.

27. Erasmus JH, Rossi SL, Weaver SC. Development of vaccines for Chikungunya fever. J Infect Dis 2016;214:S488-96.

28. European Centre for Disease Prevention and Control. Microcephaly in Brazil potentially linked to the Zika virus epidemic. Stockholm: ECDC; 2015. Available from: http://ecdc.europa.eu/en/press/news/_layouts/forms/News_Di spForm.aspx?.

29. European Centre for Disease Prevention and Control. Rapid risk assessment: Zika virus infection outbreak, French Polynesia. 14 February 2014. Stockholm: ECDC; 2014.

30. European Centre for Disease Prevention and Control. Zika virus disease epidemic: potential association with microcephaly and Guillain-Barré syndrome (first update), 21 January 2016. Available from: https://ecdc.europa.eu/en/publications-data/rapid-risk-assessment-zika-virus-disease-epidemic-potential-association

31. European Centre for Disease Prevention and Control. Zika virus and safety of substances of human origin A guide for preparedness activities in Europe. 2016. Available from: https:/ecdc.europa.eu/sites/portal/files/media/en/publications/Publications/Zika-virus-safety-of-substances-of-humanorigin.pdf.

32. Fagbami AH. Zika virus infections in Nigeria: virological and seroepidemiological investigations in Oyo State. J Hyg (Lond) 1979;83:213-9.

33. Failloux AB, Vazeille M, Rodhain F. Geographic genetic variation in populations of the dengue virus vector Aedes aegypti. J Mol Evolut 2002;55:653-63.

34. Faria NR, Azevedo Rdo S, et al. Zika virus in the Americas: early epidemiological and genetic findings. Science 2016; 352:345-9.

35. Faye O, Freire CC, Iamarino A, et al. Molecular evolution of Zika virus during its emergence in the 20(th) century. PLoS Negl Trop Dis 2014;8:e2636.

36. Fokam EB, Levai LD, Guzman H, et al. Silent circulation of arboviruses in Cameroon. East Afr Med J 2010; 87:262-8.

37. Fonseca K, Meatherall B, Zarra D, et al. First case of Zika virus infection in a returning Canadian traveler. Am J Trop Med Hyg 2014;91:1035-8.

38. Foy BD, Kobylinski KC, Chilson Foy JL, et al. Probable nonvector-borne transmission of Zika virus, Colorado, USA. Emerg Infect Dis 2011;17:880-2.

39. Gasperi G, Bellini R, Malacrida AR, et al. A new threat looming over the Mediterranean basin: emergence of viral diseases transmitted by Aedes albopictus mosquitoes. PLoS Negl Trop Dis 2012;6:e1836.

40. Gérardin P, Guernier V, Perrau J, et al. Estimating Chikungunya prevalence in La Réunion Island outbreak by serosurveys: two methods for two critical times of the epidemic. BMC Infect Dis 2008;8:99.

41. Goorhuis A, von Eije KJ, Douma RA, et al. Zika virus and the risk of imported infection in returned travelers: implications for clinical care. Travel Med Infect Dis 2016;14:13-5.

42. Gould EA, Gallian P, De Lamballerie X, et al. First cases of autochthonous dengue fever and chikungunya fever in France: From bad dream to reality! Clin Microbiol Infect 2010; $16: 1702-4$.

43. Gourinat A, O'Connor O, Calvez E, et al. Detection of Zika virus in urine. Emerg Infect Dis 2015;21:e6.

44. Haddow AJ, Williams M, Woodall J, et al. Twelve isolations of Zika virus from Aedes (Stegomyia) africanus (Theobald) taken in and above a Uganda forest. Bull World Health Organ 1964;3:57-69. 
45. Halstead SB, Scanlon JE, Umpaivit P, et al. Epidemiologic studies in the Bangkok Metropolitan area, Dengue and Chikungunya virus in man in Thailand, 1962-64. IV Am J Trop Med Hyg 1969;18:997-1021.

46. Hamel R, Liégeois F, Wichit S, et al. Zika virus: epidemiology, clinical features and host-virus interactions. Microbes Infect 2016;18:441-9.

47. Hawley WA, Reiter P, Copeland RS, et al. Aedes albopictus in North America: probable introduction in used tires from Northern Asia. Science 1987;236:1114-16.

48. Heang V, Yasuda C, Ngan C, et al. Zika virus from fever syndromic surveillance in Cambodia. Am J Trop Med Hyg 2011;85:183.

49. Heang V, Yasuda CY, Sovann L, et al. Zika virus infection, Cambodia, 2010. Emerg Infect Dis 2012;18:349-51.

50. Hearn P, Atkinson B, Hewson R, et al. Identification of the first case of imported Zika fever to the UK: a novel sample type for diagnostic purposes and support for a potential nonvectorborne route of transmission. Am J Trop Med Hyg 2014;91:6.

51. Hennessey M, Fischer M, Staples JE. Zika virus spreads to new areas-region of the Americas, May 2015-January 2016. MMWR Morb Mortal Wkly Rep 2016;65:55-8.

52. Herriman R. Transfusion-associated Zika virus reported in Brazil. 18 December 2015. Outbreak News Today; 2015. Available from: http://outbreaknewstoday.com/transfusionassociated-zika-virus-reported-in-brazil- 76935/.

53. Higgs S, Vanlandingham D. Chikungunya virus and its mosquito vectors. Vector Borne Zoon Dis 2015;15:231-40.

54. Hills SL, Russell K, Hennessey M, et al. Transmission of Zika virus through sexual contact with travelers to areas of ongoing transmission: continental United States, 2016. MMWR Morb Mortal Wkly Rep 2016;65:215-6.

55. Hynes NA. Zika virus. Available from: http://www.hopkinsguides.com/.

56. Juliano SA, O'Meara GF, Morrill JR, et al. Desiccation and thermal tolerance of eggs and the coexistence of competing mosquitoes. Oecologia 2002;130:458-69.

57. Jupp PG, McIntosh BM. Aedes furcifer and other mosquitoes as vectors of chikungunya virus at Mica, Northeastern Transvaal, South Africa. J Am Mosq Control Assoc 1990; 6:415-20

58. Jupp PG, McIntosh BM, Monath TP. Chikungunya virus disease, The arboviruses: epidemiology and ecology. Vol. II. Boca Raton: FLCRC Press; 1988.

59. Kariuki Njenga M, Nderitu L, Ledermann JP, et al. Tracking epidemic chikungunya virus into the Indian Ocean from East Africa. J Gen Virol 2008;89:2754-60.

60. Karwowski MP, Nelson JM, Staples JE, et al. Zika virus disease: a CDC update for pediatric health care providers. Pediatrics 2016;137.

61. Kaur P, Ponniah M, Murhekar MV, et al. Chikungunya outbreak, South India 2006. Emerg Infect Dis 2008;14:1623-5.

62. Khormi HM, Kumar L. Climate change and the potential global distribution of Aedes aegypti: spatial modelling using GIS and CLIMEX. Geospat Health 2014;8:405-15.

63. Kraemer MU, Sinka ME, Duda KA, et al. The global distribution of the arbovirus vectors Aedes aegypti and Ae. albopictus. Elife 2015;4:e08347.

64. Kuehnert MJ, Basavaraju SV, Moseley RR, et al. Screening of blood donations for Zika virus infection - Puerto Rico, April 3-June 11, 2016. MMWR Morb Mortal Wkly Rep 2016;65:627-8.

65. Kularatne SA, Gihan MC, Weerasinghe SC, et al. Concurrent outbreaks of chikungunya and dengue fever in Kandy, Sri Lanka, 2006-07: a comparative analysis of clinical and laboratory features. Postgrad Med J 2009;85:342-6.

66. Kutsuna S, Kato Y, Takasaki T, et al. Two cases of Zika fever imported from French Polynesia to Japan, December 2013 to January 2014. Euro Surveill 2014;19:206-83.

67. Lanciotti RS, Valadere AM. Transcontinental movement of asian genotype chikungunya virus. Emerg Infect Dis 2014;20:1400-2.

68. Lanteri MC, Kleinman SH, Glynn SA, et al. Zika virus: a new threat to the safety of the blood supply with worldwide impact and implications. Transfusion 2016;56:1907-14.

69. Laras K, Sukri NC, Larasati RP, et al. Tracking the re-emergence of epidemic chikungunya virus in Indonesia. Trans $\mathrm{R}$ Soc Trop Med Hyg 2005;99:128-41.

70. Lazear HM, Govero J, Smith AM, et al. A mouse model of Zika virus pathogenesis. Cell Host Microbe 2016;19:720-30.

71. Leparc-Goffart I, Nougairede A, Cassadou S, et al. Chikungunya in the Americas. Lancet 2014;383:514.

72. Levitt NH, Ramsburg HH, Hasty SE, et al. Development of an attenuated strain of chikungunya virus for use in vaccine production. Vaccine 1986;4:157-62.

73. Lindsey NP, Prince HE, Kosoy O, et al. Chikungunya virus infections among travelers: United States, 2010-2013. Am J Trop Med Hyg 2015;92:82-7.

74. Lustig Y, Mendelson E, Paran N, et al. Detection of Zika virus RNA in whole blood of imported Zika virus disease cases up to 2 months after symptom onset, Israel, December 2015 to April 2016. Euro Surveill 2016;21:30269.

75. Malet H, Vial A, Musso D. Epidemiological and statistiques health information bulletin [in French]. Papeete, French Polynesia: Health Surveillance Office. Available from: http:// www.hygiene-publique.gov.pdf/.

76. Marano G, Pupella S, Vaglio S, et al. Zika virus and the neverending story of emerging pathogens and Transfusion Medicine. Blood Transfus 2016;14:95-100.

77. Martines RB, Bhatnagar J, Keating MK, et al. Evidence of Zika virus infection in brain and placental tissues from two congenitally infected newborns and two fetal losses - Brazil, 2015. Morb Mortal Wkly Rep 2016;65:159-60.

78. McCarthy M. First US case of Zika virus infection is identified in Texas. BMJ 2016;352:i212.

79. Medlock JM, Hansford KM, Schaffner F, et al. A review of the invasive mosquitoes in Europe: Ecology, public health risks, and control options. Vector Borne Zoonotic Dis 2012;12: 435-47.

80. Ministry of Health of Brazil. The Ministry of Health announces epidemiological bulletin. Available from: http://portalsaude.saude.gov.br/index.php/cidadao/principal/a gencia-saude/20805. Accessed January 28, 2016.

81. Ministry of Health of Brazil, Secretary of Health of the State of Bahia. Epidemiological situation of arboviruses. Bull Epidemiol 2015:11.

82. Mlakar J, Korva M, Tul N, et al. Zika Virus associated with microcephaly. N Engl J Med 2016;374:951-8.

83. Mohan A, Kiran DH, Manohar IC, Kumar DP. Epidemiology, clinical manifestations, and diagnosis of Chikungunya fever: lessons learned from the re-emerging epidemic. Indian $\mathrm{J}$ Dermatol 2010;55:54-63.

84. Mombouli JV, Bitsindou P, Elion DO, et al. Chikungunya virus infection, Brazzaville, Republic of Congo, 2011. Emerg Infect Dis 2013;19:1542-3.

85. Monaghan AJ, Morin CW, Steinhoff DF, et al. On the seasonal occurrence and abundance of the Zika virus vector mosquito 
Aedes aegypti in the contiguous United States. PLoS Curr 2016;8.

86. Motta IJF, Spencer BR, Cordeiro da Silva SG, et al. Evidence for transmission of Zika virus by platelet transfusion. N Engl J Med 2016;375:1101-3.

87. Musso D. Zika virus transmission from French Polynesia to Brazil. Emerg Infect Dis 2015;21:1887.

88. Musso D, Baud D, Gubler DJ. Zika virus: what do we know? Clin Microbiol Infect 2016;22:494-6.

89. Musso D, Gubler DJ. Zika virus. Clin Microbiol Rev 2016;29:487-524.

90. Musso D, Nhan T, Robin E, et al. Potential for Zika virus transmission through blood transfusion demonstrated during an outbreak in French Polynesia, November 2013 to February 2014. Euro Surveill 2014;19.

91. Musso D, Nilles EJ, Cao-Lormeau VM. Rapid spread of emerging Zika virus in the Pacific area. Clin Microbiol Infect 2014;20:595-6.

92. Musso D, Roche C, Nhan TX, et al. Detection of Zika virus in saliva. J Clin Virol 2015;68:53e5.

93. Musso D, Teissier A, Rouault E, et al. Detection of Chikungunya virus in saliva and urine. Virol J 2016;13:102.

94. Muyembe-Tamfum JJ, Peyrefitte CN, Yogolelo R, et al. Epidemic of chikungunya virus in 1999 and 2000 in the Democratic Republic of the Congo. Med Trop (Mars) 2003;63:637-8.

95. Ng LC, Tan LK, Tan CH, et al. Entomologic and virologic investigation of chikungunya, Singapore. Emerg Infect Dis 2009; 15:1243-44.

96. Oliveira Melo AS, Malinger G, Ximenes R, et al. Zika virus intrauterine infection causes fetal brain abnormality and microcephaly: tip of the iceberg? Ultrasound Obstet Gynecol 2016;47:6e7.

97. Olson JG, Ksiazek TG, Suhandiman, Triwibowo. Zika virus, a cause of fever in Central Java, Indonesia. Trans R Soc Trop Med Hyg 1981;75:389-93.

98. Paixão ES, Barreto F, Teixeira MG, et al. History, epidemiology, and clinical manifestations of Zika: a systematic review. Am J Public Health 2016;106:606-12.

99. Pan American Health Organization (PAHO). Epidemiological Alert Chikungunya and dengue fever in the Americas-29 August 2014. Available from: http://www.paho.org/

100. Pan American Health Organization, World Health Organization, Regional Office for the Americas. Epidemiological alert: neurological syndrome, congenital anomalies, and Zika virus infection. Available from: http://www.paho.org/

101. Pan American Health Organization/World Health Organization (PAHO/WHO). Regional Zika Epidemiological Update (Americas): 2 June 2016. Available from: http://www.paho.org/hq/index.php?option=com_content\&vie $\mathrm{w}=$ article \&id $=11599 \&$ Itemid $=41691$.

102. Paty M, Six C, Charlet F, et al. Large number of imported chikungunya cases in mainland France, 2014: a challenge for surveillance and response. Euro Surveill 2014;19:208-56.

103. Paupy C, Delatte H, Bagny L, et al. Aedes albopictus, an arbovirus vector: from the darkness to the light. Microbes Infect 2009; 11:1177-85.

104. Pellissier A. Serological investigation on the incidence of neurotropic viruses in French Equatorial Africa. Bull Soc Pathol Exot Filiales 1954;47:223-7.

105. Pertersen LR, Bush MP. Transfusion-transmitted arboviruses. Vox Sang 2010;98:495-503.

106. Peyrefitte CN, Bessaud M, Pastorino BA, et al. Circulation of chikungunya virus in Gabon, 2006-2007. J Med Virol 2008;80:430-3.
107. Peyrefitte CN, Rousset D, Pastorino BA, et al. Chikungunya virus, Cameroon, 2006. Emerg Infect Dis 2007;13:768-71.

108. Pialoux G, Gaüzère BA, Jauréguiberry S, et al. Chikungunya, an epidemic arbovirosis. Lancet Infect Dis 2007;7:319-27.

109. Powers AM, Logue $\mathrm{CH}$. Changing patterns of chikungunya virus: re-emergence of a zoonotic arbovirus. J Gen Virol 2007;88:2363-77.

110. Pyke AT, Daly M, Cameron J, et al. Imported Zika virus infection from the Cook Islands into Australia, 2014. PLoS Curr 2014;2:6.

111. Quanguin N, Wang L, Cheng G. Potential for treament and a Zika virus vaccine. Curr Opin Pediatr 2017;29:114-21.

112. Ramsauer K, Tangy F. Chikungunya virus vaccines: viral vector-based approaches. J Infect Dis 2016;214:S500-5.

113. Ratsitorahina M, Harisoa J, Ratovonjato J, et al. Outbreak of dengue and chikungunya fevers, toamasina, Madagascar, 2006. Emerg Infect Dis 2008;14:1135-7.

114. Reiter P, Fontenille D, Paupy C. Aedes albopictus as an epidemic vector of chikungunya virus: Another emerging problem? Lancet Infect Dis 2006;6:463-4.

115. Rezza G, Nicoletti L, Angelini R, et al. Infection with chikungunya virus in Italy: an outbreak in a temperate region. Lancet 2007;370:1840-6.

116. Ross RW. The Newala epidemic.III. The virus: isolation, pathogenic properties and relationship to the epidemic. J Hyg 1956;54:177-91.

117. Roth A, Mercier A, Lepers C, et al. Concurrent outbreaks of dengue, chikungunya and Zika virus infections: an unprecedented epidemic wave of mosquito-borne viruses in the Pacific 2012-2014. Euro Surveill 2014;19:20929.

118. Salvador FS, Fujita DM. Entry routes for Zika virus in Brazil after 2014 World Cup: new possibilities. Travel Med Infect Dis $2016 ; 14: 49-51$.

119. Sam IC, Chan YF, Chan SY, et al. Chikungunya virus of Asian and Central/East African genotypes in Malaysia. J Clin Virol 2009;46:180-3.

120. Sam IC, Loong SK, Michael IC, et al. Genotypic and phenotypic characterization of chikungunya virus of different genotypes from Malaysia. PLoS One 2012;7:e50476.

121. Sanyaolu A, Okorie C, Badaru O, et al. Chikungunya Epidemiology: a global perspective. SM J Publ Health Epidemiol 2016;2:1028.

122. Sarkar JK, Chatterjee SN, Chakravarty SK. Haemorrhagic fever in Calcutta: some epidemiological observations. Indian J Med Res 1964;52:651-4.

123. Savage HM, Ledermann JP, Yug L, et al. Incrimination of Aedes (Stegomyia) hensilli Farner as an epidemic vector of Chikungunya virus on Yap Island, Federated States of Micronesia, 2013. Am J Trop Med Hyg 2015;92:429-36.

124. Schuffenecker I, Iteman I, Michault A, Murri S, et al. Genome microevolution of chikungunya viruses causing the Indian Ocean outbreak. PLoS Med 2006;3:e263.

125. Sergon K, Njuguna C, Kalani R, et al. Seroprevalence of chikungunya virus (CHIKV) infection on Lamu Island, Kenya, October 2004. Am J Trop Med Hyg 2008;78:333-7.

126. Simon F, Savini H, Parola P. Chikungunya: a paradigm of emergence and globalization of vector-borne diseases. Med Clin North Am 2008;92:1323-43.

127. Stramer SL, Hollinger FB, Katz LM, et al. Emerging infectious disease agents and their potential threat to transfusion safety. Transfusion. 2009;49:1-29S.

128. Sudeep AB, Parashar D. Chikungunya: an overview. J Biosci 2008;33:443-9.

129. Tan KK, Sy AKD, Tandoc AO, et al. Independent emergence 
of the cosmopolitan asian chikungunya virus, Philippines 2012. Sci Rep 2015;23;5:12279.

130. Tappe D, Rissland J, Gabriel M, et al. First case of laboratory-confirmed Zika virus infection imported into Europe, November 2013. Euro Surveill 2014;19:206-85.

131. Theamboonlers A, Rianthavorn P, Praianantathavorn K, et al. Clinical and molecular characterization of chikungunya virus in south Thailand. Jpn J Infect Dis 2009;62:303-5.

132. The Conversationist. Zika virus: mosquitoes and travel patterns will determine spread of virus. Available from: http:/theconversation.com/zika-virus-mosquitoes-and-travelpatterns-will-determine-spread-of-virus-53484. Accessed 18 November 2016.

133. Thiberville SD, Moyen N, Maguiraga LD, et al. Chikungunya fever: epidemiology, clinical syndrome, pathogenesis and therapy. Antiviral Res 2013;99:345-70.

134. Tognarelli J, Ulloa S, Villagra E, et al. A report on the outbreak of Zika virus on Easter Island, South Pacific, 2014. Arch Virol 2016;161:665-8.

135. Tomasello D, Schlagenhauf P. Chikungunya and dengue autochthonous cases in Europe, 2007-2012. Travel Med Infect Dis 2013;11:274-84.

136. Tsetsarkin KA, Chen R, Yun R, et al. Multi-peaked adaptive landscape for chikungunya virus evolution predicts continued fitness optimization in Aedes albopictus mosquitoes. Nat Commun 2014;5:4084.

137. Tsetsarkin KA, Vanlandingham DL, McGee CE, Higgs S. A single mutation in chikungunya virus affects vector specificity and epidemic potential. PLoS Pathog 2007;3:e201.

138. Turell MJ, Beaman JR, Tammariello RF. Susceptibility of selected strains of Aedes aegypti and Aedes albopictus (Diptera: Culicidae) to chikungunya virus. J Med Entomol 1992;29:49-53.

139. Vorou R. Zika virus, vectors, reservoirs, amplifying hosts, and their potential to spread worldwide: what we know and what we should investigate urgently. Int J Infect Dis 2016;48:85-90.

140. Wæhre T, Maagard A, Tappe D, et al. Zika virus infection after travel to Tahiti, December 2013. Emerg Infect Dis 2014;20:1412-4.

141. Wahid B, Ali A, Rafique S, Idrees M. Zika: as an emergent epidemic. Asian Pac J Trop Med 2016;9:723-9.

142. Wang JN, Ling F. Zika virus infection and microcephaly: evidence for a causal link. Int J Environ Res Public Health 2016;13:1031.

143. Wangchuk S, Chinnawirotpisan P, Dorji T, et al. Chikungunya fever outbreak, Bhutan, 2012. Emerg Infect Dis 2013;19:1681-4. 144. Weaver SC. Arrival of chikungunya virus in the new world: prospects for spread and impact on public health. PLoS Negl Trop Dis 2014;8:e2921.

145. Wong PS, Li MZ, Chong CS, et al. Aedes (Stegomyia) albopictus (Skuse): a potential vector of Zika virus in Singapore. PLoS Negl Trop Dis 2013;7:e2348.

146. World Health Organization. Chikungunya. Available from: http://www.who.int/denguecontrol/arbo-viral/other_arboviral chikungunya/en/.

147. World Health Organization. Current Zika product pipeline. 2016. 03 March Report. Available from: http://www.who.int/ blueprint/priority-diseases/key-action/zika-rd-pipeline.pdf

148. World Health Organization. Guidelines for prevention and control of Chikungunya fever. 2009. Available from: http://apps.who.int/

149. World Health Organization. Pacific syndromic surveillance report. Week 13, ending 30th March, 2014. Manila, Philippines: World Health Organization Western Pacific Region; 2014.

150. World Health Organization. WHO Director-General summarizes the outcome of the Emergency Committee on Zika. 1 February 2016. Geneva: WHO; 2016. Available at: http://www.who.int/mediacentre/news/statements/2016/emergency-committee-zika-microcephaly/en/.

151. World Health Organization. Zika virus. Available at: http://www.wpro.who.int/mediacentre/factsheets/fs_0518201 5 zika/en/. Accessed 25 November 2016.

152. $\overline{\mathrm{Wu}} \mathrm{D}, \mathrm{Wu} \mathrm{J}$, Zhang Q, et al. Chikungunya outbreak in Guangdong Province, China, 2010. Emerg Infect Dis 2012;18:493-5.

153. Yergolka PN, Tandale BV, Arankalle VA, et al. Chikungunya outbreaks caused by African genotype, India. Emerg Infect Dis $2006 ; 12: 1580-3$.

154. Zammarchi L, Stella G, Mantella A, et al. Zika virus infections imported to Italy: clinical, immunological and virological findings, and public health implications. J Clin Virol 2015;63:32-5.

155. Zanluca C, Melo VC, Mosimann AL, et al. First report of autochthonous transmission of Zika virus in Brazil. Mem Inst Oswaldo Cruz 2015;110:569-72.

156.Zika Virus Net. Aedes aegypti. Available from: http:// www.zikavirusnet.com/aedes-aegypti.html. Accessed: 18 November 2016.

157. Zika Virus Net. Aedes albopictus. Available from: http:// www.zikavirusnet.com/aedes-albopictus.html. Accessed: 18 November 2016.

158. Zeller H, Bortel WV, Sudre B. Chikungunya: Its History in Africa and Asia and Its Spread to New Regions in 2013-2014. J Infect Dis 2016;214:S436-40. 